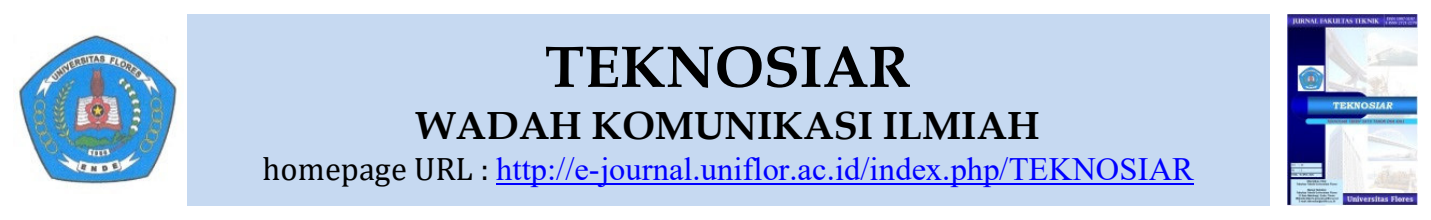

\title{
Studi Sensor Curah Hujan Untuk Pemisahan Air Bersih Dari Air Kotor Pada Sistem Bak Tadah Hujan
}

\author{
*Andreas Luis ${ }^{1}$, DVX Deddy Kurniawan ${ }^{2}$ \\ 1,2,3 Program Studi Arsitektur, Fakultas Teknik, Universitas Flores, Ende. \\ ${ }^{*}$ korespondensi: andreasluis2020@gmail.com
}

Received:28-03-2020 Revised: 12-04-2020 Accepted:17-04-2020

\begin{abstract}
ABSTRAC
Collected water on the common rain harvesting system were not been so well because of dust contain. it is necessary to separate clean water from dirty water. The research was conducted on the rainfall recognition method for separating clean water from dirty water on the rain harvesting system. Separation can be done by including rainfall sensor on the rain harvesting system. The research resulted in detailed design of rainfall sensor that were easy to build so could be easily implemented by public. The research also suggesting for further research.
\end{abstract}

Keywords: Sensor; Rain; harvesting; water; clean

\begin{abstract}
Perolehan air bersih pada sistem bak tadah hujan konvensional tidak maksimal karena mengandung debu kotoran. Pemisahan air bersih dari air kotor perlu dilakukan. Penelitian dilakukan pada metode pengenalan curah hujan untuk pemisahan air bersih dari air kotor pada sistem bak tadah hujan. Pemisahan dapat dilakukan dengan bantuan sensor curah hujan. Penelitian menghasilkan rumusan desain sensor curah hujan yang mudah dibuat dengan menggunakan bahan seadanya agar mudah dimanfaatkan oleh masyarakat luas untuk pemenuhan kebutuhan air bersih. Penelitian juga menghasilkan saran untuk penelitian lanjutan.
\end{abstract}

Keywords: Sensor; Rain; harvesting; Air; bersih

\section{PENDAHULUAN}

Permasalahan air bersih cukup dirasakan oleh penduduk dunia. Pengadaan air bersih sering menjadi kendala bagi masyarakat di dataran tinggi. Medan berbukit menyebabkan perolehan air bersih dari sungai menjadi sulit dan biaya pembangunan irigasi menjadi mahal. Wilayah Indonesia beriklim tropis, yang berarti curah hujan nya tinggi. Sistem penangkap air hujan dicoba sebagai upaya pemenuhan kebutuhan air bersih. Air hujan yang telah diperoleh akan digunakan untuk memenuhi kebutuhan air bersih. Diharapkan dengan sistem penangkap air hujan biaya pengadaan air bersih dapat ditekan.

Sistem penangkap hujan sering digunakan oleh masyarakat Indonesia; lebih dikenal sebagai bak tadah hujan. Sistem bak tadah hujan konvensional terdiri dari atap, talang, dan bak tampung. Permasalahan yang sering terjadi yaitu air yang diperoleh tidak cukup bersih karena terkontaminasi debu permukaan atap. Sebelum hujan turun bidang permukaan atap dan talang dalam keadaan kering dan berdebu. Luas permukaan atap mempengaruhi jumlah debu. Debu ada karena terbawa oleh angin dari lingkungan di sekitarnya. Angin juga mempengaruhi jumlah debu permukaan atap.

TEKNOSIAR Volume 14, No.01, April 2020

p-ISSN 1907-5197 (versi cetak) e-ISSN 2721-2270 (versi online) 
Saat hujan turun dan membasahi permukaan atap aliran air telah bercampur debu. Butuh beberapa waktu hingga seluruh debu terbawa air.

Kontaminasi debu pada air hanya terjadi pada awal proses penampungan. Setelah permukaan atap bersih dari debu, air yang mengalir sudah bebas debu. Dengan memisahkan air bercampur debu dari air bersih, kualitas perolehan air bersih lebih maksimal. Pemisahan dilakukan dengan memisahkan aliran air bersih dan aliran air kotor. Aliran air bercampur debu pada awal proses penampungan diarahkan ke saluran terpisah. Setelah seluruh debu permukaan atap telah terbawa air, aliran air bersih diarahkan ke bak penampung air bersih.

\section{METODE PENELITIAN}

Penelitian dilakukan pada metode pengenalan curah hujan. Pengenalan curah hujan dilakukan untuk menentukan waktu pemisahan air bersih dari air kotor pada sistem bak tadah hujan. Penelitian menghasilkan desain sensor curah hujan yang dirakit dan diuji di lingkungan nyata. Luaran penelitian berupa desain sensor curah hujan sederhana untuk mengenali curah hujan yang sedang terjadi dan mengaktifkan mekanisme pemisahan air bersih dari air kotor.

\section{HASIL DAN PEMBAHASAN}

Pembersihan debu oleh air hujan dipengaruhi oleh curah hujan yang terjadi. Pada saat hujan, seluruh permukaan atap basah secara merata dan bersamaan meskipun luas permukaan atap bervariasi. Selisih luas permukaan atap tidak berpengaruh terhadap waktu yang dibutuhkan hujan untuk membasahi seluruh permukaan atap secara merata. Curah hujan yang sama menyebabkan seluruh debu terbawa air dan bersih pada waktu yang sama meskipun luas permukaan atap berbeda. Penutupan saluran air kotor dilakukan pada waktu yang sama meskipun pada luas permukaan atap yang berbeda.

Waktu yang tepat untuk menutup saluran air kotor dibedakan menurut curah hujan yang terjadi. Curah hujan diukur dengan nilai resapan tanah. Curah hujan dapat juga diukur dengan nilai resapan air pada busa spoon. Metode pemisahan air kotor dari air bersih pada sistem penangkap hujan dapat disertakan dengan pengatur waktu. Pengatur waktu mengenali tingkatan curah hujan yang terjadi. Resapan air pada busa spoon digunakan sebagai pengatur waktu.

Identifikasi curah hujan dapat dilakukan dengan nilai resapan air pada bahan busa. Dua busa dengan ukuran yang sama dibasahi oleh hujan yang sama akan menyerap air dalam jumlah yang sama dan mencapai berat yang sama pada waktu yang sama tergantung curah hujan yang terjadi. Semakin deras hujan yang turun semakin cepat busa menampung air hingga mencapai berat maksimal. Berat busa dapat digunakan sebagai penanda waktu penutupan saluran air kotor.

Parameter buka-tutup aliran yang dapat digunakan secara global di masyarakat luas yaitu curah hujan. Waktu yang tepat untuk buka-tutup aliran tidak selalu sama tergantung karakteristik hujan yang terjadi. Bak tadah hujan dapat dilengkapi dengan sistem pengenalan curah hujan.

Sensor curah hujan didesain sesederhana mungkin agar dapat menjangkau masyarakat luas. Desain sensor curah hujan harus mudah dikerjakan dengan menggunakan bahan yang mudah didapat dan harga terjangkau. Bahan utama sensor curah hujan yaitu busa. Busa merupakan bahan sintetis yang dapat menyerap air. Daya serap busa bergantung pada jenis dan ketebalan busa. Bahan busa dapat digunakan sebagai media penyerapan air untuk menilai curah hujan yang terjadi. Dengan mengetahui curah hujan yang terjadi waktu penutupan saluran air kotor dapat ditentukan.

a. Desain sensor curah hujan

Sensor curah hujan dibuat dengan prinsip timbangan sederhana. Berat air yang meresap pada busa mengaktifkan mekanisme penutupan saluran air kotor.

TEKNOSIAR Volume 14, No.01, April 2020

p-ISSN 1907-5197 (versi cetak) e-ISSN 2721-2270 (versi online) 


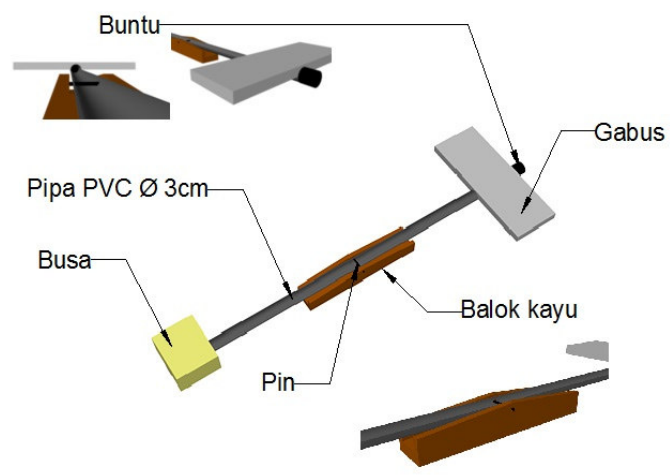

Gambar 2. Sensor curah hujan

b. Cara kerja sensor curah hujan

Sumber : Dokumen pribadi 1 Oktober 2015

1) Posisi satu saluran air kotor terbuka.

Pada posisi satu sensor berada dalam keadaan seimbang. Sensor dalam keadaan kering karena tidak terjadi hujan. Busa tidak basah dan tidak ada genangan air pada sensor. Pada posisi satu saluran air kotor terbuka.

2) Posisi dua saluran air kotor masih terbuka.

Pada posisi dua terjadi genangan awal pada sensor. Pukulan air hujan pada bidang gabus akan memperbesar kecenderungan genangan air terkumpul pada tabung pipa di ujung sensor. Busa pada sensor belum cukup basah sehingga belum cukup berat untuk mengimbangi berat air pada sisi tabung.

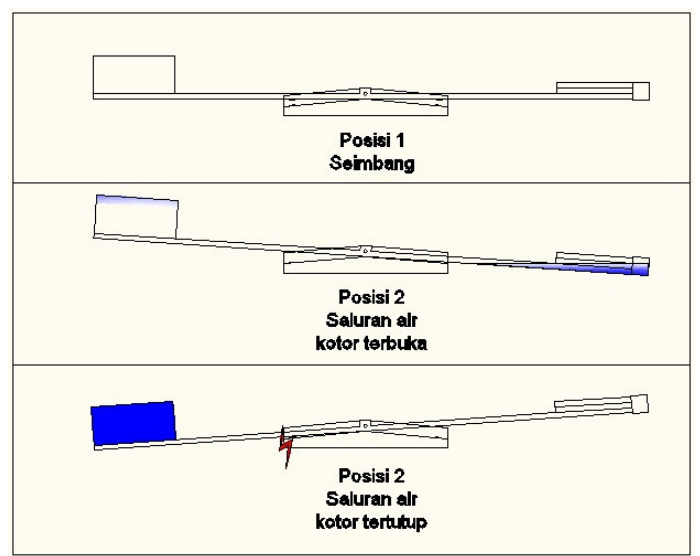

Gambar 3. Cara kerja sensor curah hujan

Sumber : Dokumen pribadi 1 Oktober 2015

3) Posisi tiga saluran air kotor tertutup dan saluran air bersih terbuka.

Pada posisi tiga busa sudah cukup banyak menampung air. Tampungan air pada busa sangat tergantung pada curah hujan. Ketebalan busa yang digunakan disesuaikan dengan perkiraan waktu yang tepat untuk menutup saluran air kotor. Perubahan keseimbangan sensor akibat berat air pada busa dimanfaatkan untuk mengaktifkan mekanisme penutupan saluran air kotor. Mekanisme penutupan saluran air kotor dapat berupa lampu indikator, suara alarm atau mekanisme penutupan otomatis secara elektronik. Posisi tiga saluran air kotor tertutup, saluran air bersih terbuka, dan air bersih mengalir ke bak penampung. Setelah hujan reda busa menjadi ringan karena kering. Sensor kembali ke posisi satu, saluran air kotor terbuka, dan selanjutnya menunggu hujan berikutnya untuk mengerjakan tugasnya sebagai sensor curah hujan.

TEKNOSIAR Volume 14, No.01, April 2020

p-ISSN 1907-5197 (versi cetak) e-ISSN 2721-2270 (versi online) 


\section{KESIMPULAN}

Bak tadah hujan perlu dilengkapi dengan sensor curah hujan untuk kualitas hasil yang lebih baik. Penentuan waktu buka-tutup aliran air bersih dan air kotor didasarkan pada curah hujan yang terjadi. Sensor curah hujan mudah dikerjakan dengan menggunakan bahan-bahan seadanya. Desain sensor curah hujan dapat dibuat sendiri dengan memahami prinsip dasar sensor curah hujan.

Mekanisme buka tutup aliran sebaiknya dapat bekerja otomatis dengan energi mandiri. Penelitian selanjutnya perlu dilakukan pada mekanisme otomatis buka-tutup aliran air kotor dan air bersih untuk memungkinkan sistem penangkap air bekerja otomatis dengan energi mandiri.

\section{DAFTAR USTAKA}

Mun, J. S., and M. Y. Han. "Design and operational parameters of a rooftop rainwater harvesting system: definition, sensitivity and verification." Journal of Environmental Management 93.1 (2012): 147-153.

Mun, J. S., \& Han, M. Y. (2012). Design and operational parameters of a rooftop rainwater harvesting system: definition, sensitivity and verification. Journal of Environmental Management, 93(1), 147-153.

MUN, J. S.; HAN, M. Y. Design and operational parameters of a rooftop rainwater harvesting system: definition, sensitivity and verification. Journal of Environmental Management, 2012, 93.1: 147-153.

Roman, David, et al. "Design and modeling of an adaptively controlled rainwater harvesting system." Water 9.12 (2017): 974.

Roman, D., Braga, A., Shetty, N., \& Culligan, P. (2017). Design and modeling of an adaptively controlled rainwater harvesting system. Water, 9(12), 974.

ROMAN, David, et al. Design and modeling of an adaptively controlled rainwater harvesting system. Water, 2017, 9.12: 974.

Ward, Sarah, F. A. Memon, and David Butler. "Rainwater harvesting: model-based design evaluation." Water Science and Technology 61.1 (2010): 85-96.

Ward, S., Memon, F. A., \& Butler, D. (2010). Rainwater harvesting: model-based design evaluation. Water Science and Technology, 61(1), 85-96.

WARD, Sarah; MEMON, F. A.; BUTLER, David. Rainwater harvesting: model-based design evaluation. Water Science and Technology, 2010, 61.1: 85-96.

Jones, Matthew P., and William F. Hunt. "Performance of rainwater harvesting systems in the southeastern United States." Resources, Conservation and Recycling 54.10 (2010): 623-629.

Jones, M. P., \& Hunt, W. F. (2010). Performance of rainwater harvesting systems in the southeastern United States. Resources, Conservation and Recycling, 54(10), 623-629.

JONES, Matthew P.; HUNT, William F. Performance of rainwater harvesting systems in the southeastern United States. Resources, Conservation and Recycling, 2010, 54.10: 623-629.

TEKNOSIAR Volume 14, No.01, April 2020

p-ISSN 1907-5197 (versi cetak) e-ISSN 2721-2270 (versi online) 